\title{
Microbes evolve, microbes survive
}

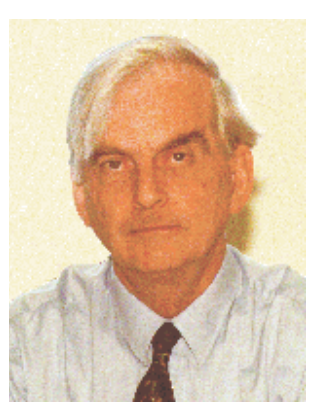

T Hugh Pennington President, Society for General Microbiology, Emeritus Professor of Bacteriology, University of Aberdeen, Medical School Building, Foresterhill, Aberdeen, AB25 2ZD, UK Tel.: + 44122453 104; Fax: +441224552692; mmb036@abdn.ac.uk
I believe that microbiologists, and

all biologists, should do everything in their power to improve the understanding of evolutionary processes. It goes without saying that our surveillance and diagnostic facilities must also be of the highest quality.'

When I was young, I believed in progress and the triumph of reason over blind faith, ignorance and superstition, delivered most notably by science. The Second World War had ended not long before, utterly destroying two cruel regimes that had drawn their life-blood from prejudice and unreason. Technology had been driven relentlessly by that war; long distance air travel was now almost routine, plastic goods had become plentiful and cheap, cathode ray tubes were on the verge of entering every home in TV sets and nuclear power was going to free us from dependence on coal, a dirty, dangerous and unreliable energy source. Great strides had been made in the improvement of human health through scientific research; Nobel Prizes had been won in 1945 for the discovery and development of penicillin by Fleming, Florey and Chain, and in 1948 by Müller for the discovery of dichloro-diphenyl-trichloroethane (DDT).

I qualified in medicine in the early 1960s and was offered a job in medical microbiology; the notion that vaccines and antibiotics had conquered infectious diseases was so strong at that time that I was urged by some of my seniors to turn it down. I have never regretted ignoring their advice. There had been straws in the wind indicating that the microbe had not gone away. But I didn't appreciate their significance until much later. In 1957 pandemic influenza Asian flu - had laid me low for a week and, as a junior hospital doctor in the early 1960s, I had had repeated crops of boils caused by a particularly virulent new strain of Staphylococcus aureus, phage type $80 / 81$. Looking back, it is clear that this time was a turning point for scientists. It was the start of a big change in their relationship with the public, marked by the publication in 1962 of Rachel Carson's 'Silent Spring'. Her target was pesticides made by the chemical industry. Her aim was to demonize them. She was successful - and her success has been sustained. The term 'pesticide' has a pejorative sense today that is quite different from the beneficient ring of 'bactericides', even though most people now know that most bacteria are harmless, or even good for health, while pests are still pests. One of her most compelling examples was the aerial spraying of large tracts of North America with DDT and its negative effects on wild bird populations. DDT was banned by the US Environmental Protection Agency in 1972. The fictional image of the more than slightly mad whitecoated scientist celebrated for the first time long ago in the novels of Mary Wollstonecraft Shelley (Frankenstein, 1817), Jules Verne and HG Wells had come true. But all the evidence clearly indicates today that Carson's destruction of the reputation of DDT was based on a massive exaggeration of its toxicity to warmblooded animals other than birds. It is also clear that, while a robust case can be made that some birds have been saved, millions of humans have died of malaria that could have been prevented by the continued use of DDT to control mosquito vectors.

Carson was right on another topic, however. Her chapter 'The Rumblings of an Avalanche' started with the words: 'If Darwin were alive today the insect world would delight and astound him with its impressive verification of his theories of the survival of the fittest.

'while... some birds have been saved, millions of humans have died of malaria that could have been prevented by the continued use of DDT'

Under the stress of intensive chemical spraying the weaker members of the insect populations are being weeded out. Now, in many areas and among many species only the strong and fit remain to defy out efforts to control them'. It is a pity that doctors prescribing antibiotics - and patients insisting on being treated with them for 
trivial and self-limiting infections - failed to heed Carson's analysis. It was not as though the selection and spread of antibiotic-resistant pathogens was a new phenomenon. Alexander Fleming had identified naturally occurring penicillinresistant staphylococci in 1942. By the late 1940s half of the strains of Staphylococcus aureus in London hospitals were penicillinase producers. Methicillin (BRL 1241) was developed in response. Its discoverers wrote in the Lancet in 1960 'Resistance to BRL 1241 comparable to that which exists to penicillin $G$ would require the ability to inactivate BRL 1241 by a new penicillinase.

$\therefore$...our ignorance of the forces driving the evolution of pathogens in the field is still profound.'

Since cultures have not been encountered showing this properly, it seems unlikely that the selection and proliferation of resistance strains will take place rapidly, if at all'. Their optimism was misplaced. Strains resistant by an entirely different mechanism appeared in less than a year. The first hospital outbreak occurred in 1963 at Queen Mary's Hospital at Carshalton, near London, spreading to eight wards, infecting 37 and killing one. Evolution continued. In Britain, for example, one of the currently dominant methicillin resistant $S$. aureus (MRSA) strains, EMRSA 16, first appeared in Northamptonshire hospitals in 1992. It spread quickly to hospitals in neighboring counties, then to London. By 2000 it was common throughout Britain; it now occurs in Ireland, Denmark, Sweden, Finland, Norway, Switzerland, Spain, Greece, Cyprus, Turkey and the USA.

It is clear that ignoring the reality of evolution carries a heavy penalty. For antibiotic-resistant bacteria and for pesticide-resistant mosquitoes the selection pressures are very visible. But our ignorance of the forces driving the evolution of pathogens in the field is still profound. That is why its products regularly take us by surprise. Good UK examples are new pathogens, such as the bovine spongiform encephalopathy (BSE)/variant Creutzfeldt-Jakob disease (vCJD) agent, Escherichia coli O157, which in 1996 infected 500 and killed 17 in an outbreak in central Scotland, and the pan-Asia strain of foot and mouth disease, which originated in North India in 1990 and spread round the world to cause the enormous British outbreak in 2001.
What is to be done? I believe that microbiologists, and all biologists, should do everything in their power to improve the understanding of evolutionary processes. It goes without saying that our surveillance and diagnostic facilities must also be of the highest quality. These activities need funding, and scientists also have a duty to explain and persuade, not only its controllers, but its source, the taxpayer, why they should be supported.

My opening lines said that I used to believe in progress. Now I am not so sure. Homeopaths are currently claiming that their remedies produced a 30 -fold death rate reduction in the 1918-1919 influenza pandemic. Many will believe this rubbish; homeopathy has never been as popular as it is today. In 2001, many organic farmers believed that their flocks and herds would be resistant to food and mouth disease they were not. And the word 'natural' is taken by most to mean good, unpolluted, health-giving and benevolent. The 'balance of nature' is an environmentalist's motto, but the natural world is not at rest - like a pair of scales with identical weights in its two pans - it is in constant flux. It is dynamic. Evolution sees to that. Neither is nature nice. John Stuart Mills' essay 'Nature' of 1873 describes it accurately: 'A single hurricane destroys the hopes of a season; a flight of locusts, or an inundation, desolates a district...the waves of the sea, like banditti seize and appropriate the wealth of the rich and the little all of the poor...Even the love of 'order' which is thought to be a following of the ways of nature, is in fact a contradiction of them. Anarchy and the Reign of Terror are overmatched in injustice, ruin, and death, by a hurricane and pestilence'.

But perhaps all is not lost. US District Judge Johen E Jones' III judgement in Tammy Kitzmiller and colleagues (plaintiffs) versus Dover Area School District and colleagues (defendants) on 20 December 2005 gives cause for hope. He said 'To be sure, Darwin's theory of evolution is imperfect. However, the fact that a scientific theory cannot yet render an explanation of every point should not be used as a pretext to thrust an untestable alternative hypothesis grounded in religion in the science classroom or to misrepresent well-established scientific propositions'. His demolition of 'intelligent design' as science is not only definitive but paradigmatic; scientists should follow its example in doing the same for all the other crackpot notions that plague us today. 
EDITORIAL - Pennington 